\title{
Divergent Perceptions of Lesbians: A Comparison of Lesbian Self-Perceptions and Heterosexual Perceptions
}

\author{
DENISE C. VISS \\ SHAWN M. BURN
}

\begin{abstract}
Social-psychological research on stereotyping was applied to lesbianism among American college students. The hypothesis that stereotypes of lesbians are often inaccurate predictors of individual lesbians was supported. Using stereotypes of lesbians identified by previous research, lesbians rated themselves on a series of bipolar stereotypical adjectives, and a comparison group of nonlesbians rated lesbians as a group on these same adjectives. Significant differences were found on 16 of the 21 adjectives. Knowing a lesbian personally did not influence heterosexuals' ratings, suggesting the resistance of stereotypes to change.
\end{abstract}

STEREOTYPES AND PREJUDICE are a part of everyday life. Individuals attribute stable traits and enduring dispositions to other people in an attempt to understand other people's actions and predict their behavior. Moreover, individuals may use these beliefs to guide their behavioral interactions with other people (Snyder \& Uranowitz, 1978).

Many social psychologists (Carroll \& Payne, 1976; Hamilton, 1976; Snyder, 1981) view stereotypes as cognitive categorizations of people that are a natural by-product of categorization processes that normally serve people well. Categorization reduces a world of infinite stimuli into a cognitively manageable number of categories (Rosch, Mervis, Gray, Johnson, \& BoyesBraem, 1976). Other social psychologists (Tajfel, 1981; Tajfel \& Turner, 1979) have noted that negative stereotypes of outgroups (groups to which a person doesn't belong) may also serve ego-enhancing needs: Putting down 
outgroups serves to bolster self-esteem by making a person feel superior to others.

Although classifying others simplifies a person's world and may bolster self-esteem, it may also provide an overly simplistic picture of a complex reality. Indeed, research indicates that people tend to overestimate the similarities of individuals within one group and to overestimate the differences between groups (Myers, 1987). Because group stereotypes are often inaccurate when it comes to individual members of groups, treating individuals on the basis of their group membership is problematic. Equally disturbing is the self-sustaining nature of these often inaccurate stereotypes of outgroups. As social stereotype researcher Snyder said:

When people have faith in their stereotypes, they may treat others in ways that actually elicit behaviors that support those stereotypes. And even if people were to develop doubts about their stereotypes, they might test them by selectively gathering evidence that appears to confirm them. Such may be the power of social stereotypes, even when they are wrong, they may create and sustain their own social reality. (quoted in Myers, 1987, p. 177)

\section{Homosexuals as a Stereotyped Group}

Stereotypes are prevalent throughout American society, but various outgroups are often the focus of negative perceptions. Homosexuals, for example, have long been considered to be deviants. Simmons (1965) reported that discernible stereotypes of at least several kinds of deviants do exist in American society and that there is a fair amount of agreement on the content of these stereotypes. One of the groups included in Simmons's study was homosexuals, along with marijuana smokers, beatniks, adulterers, and political radicals.

In the 1960s, homosexuals were rated as the third most dangerous group of individuals in the United States in a public opinion survey, outranked only by communists and atheists (Aguero, Bloch, \& Byrne, 1984). Some of the labels given to homosexuals in Simmons's (1965) study included sexually abnormal, perverted, mentally ill, maladjusted, and oversexed. Even in the world of psychology, homosexuals have been perceived negatively. It was not until 1973 that the American Psychiatric Association removed homosexuality from its official list of mental disorders.

Negative perceptions of homosexuals may give rise to both homophobia and heterosexual bias. Homophobia, especially in men, has been defined from a cultural perspective as any belief system that supports negative myths and stereotypes about homosexual people. More specifically, homophobia is a belief system that (a) holds that discrimination on the basis of sexual orientation is justifiable or (b) does not value homosexual life styles equally with heterosexual life styles (Morin \& Garfinkle, 1978). 
Heterosexual bias can be defined as the valuing of heterosexuality as superior to or more natural than homosexuality (Morin \& Garfinkle, 1978). In one study, heterosexual subjects perceived gay and lesbian couples to be less satisfied with their relationships than heterosexual couples were (Testa, Kinder, \& Ironson, 1987). This perception of gay and lesbian couples is not restricted to nonprofessionals but has also been a primary barrier between mental health professionals and their gay clients (Testa et al., 1987).

Another example of heterosexual bias was found by McDonald (1981), who investigated the content of 48 introductory psychology textbooks published in the United States over a period of 5 years (1975-1979). Of the 48 textbooks, 8 made no reference to homosexuality and 14 referred only briefly to lesbianism. Sixty percent of the textbook authors listed homosexuality as a subtopic under chapters that implied deviancy, for example, in chapters on behavior disorders, sexual dysfunction, and psychopathology. The fact that the literature on homosexuality has been dominated by research on diagnosis, cause, and cure is further evidence of its perception as deviant.

\section{Content of the Lesbian Stereotype}

Research in the United States on heterosexuals' views of homosexuals not only has revealed heterosexual bias but also has consistently indicated heterosexuals' negative views of homosexuals. Snyder and Uranowitz (1978) found that lesbian stereotypes include the views that lesbians have abusive fathers, have never had a steady boyfriend, never date men, and are rather unattractive. In Staats's (1978) study on social distance and traits given to homosexuals, it was found that increased social distance (as measured by the Bogardus Social Distance Scale) from homosexuals was correlated with using the following traits to describe homosexuals: cowardly, sly, suspicious, shrewd, stupid, impulsive, and ignorant. However, people who were less socially distant from homosexuals used these traits to describe them: individualistic, intelligent, honest, imaginative, and neat.

\section{Dearth of Research on Lesbianism in Comparison with Male Homosexuals}

Of the research on homosexuality, relatively little has focused on lesbianism. Rosen (1974) reviewed the literature in an attempt to explain this trend and suggested several possibilities. These included the domination of the psychiatric field by men, the possibility that lesbians are not under as much external pressure to seek psychiatric treatment because of society's more lenient attitudes toward female homosexuals, and the possibility that Americans may be less concerned with female sexuality in general.

The present study was concerned with the accuracy of heterosexuals' beliefs about lesbians in comparison with lesbians' self-perceptions. Several 
earlier studies have suggested that heterosexuals' perceptions of lesbians may be inaccurate, but no study has directly compared lesbians' and others' perceptions. For example, in one study, designed to determine how well both heterosexuals and homosexuals could determine the sexual orientation of individuals from videotaped interviews, $80 \%$ of the subjects could not determine the sexual preference of the persons interviewed on the videotapes (Berger, Hank, Rauzi, \& Simkins, 1987). In another study (Rosen, 1974), the self-perceptions of 26 lesbians revealed that their perceptions of themselves were quite different from what research has shown to be the views that heterosexuals have of lesbians. The women were given a list of 300 adjectives and were told to choose the adjectives they thought would best describe themselves. The adjectives most frequently chosen were capable, intelligent, sensitive, understanding, reliable, humorous, and interests wide [sic].

Some researchers have suggested that contact with a nonstereotypical member of a stereotyped group must occur for a person's stereotypes to change. Several studies, for example, have found that racial contact leads to decreased prejudice (Amir, 1969; Pettigrew, 1969). Others have noted that prejudiced individuals may simply create a special category for the nonstereotyped individual rather than alter their overall stereotype (Frieze, Parsons, Johnson, Ruble, \& Zellman, 1978; Hamilton, 1979). In the present study, we compared the group stereotypes of lesbians held by heterosexuals who knew a lesbian personally with the stereotypes held by heterosexuals who did not.

\section{Method}

\section{Design}

The survey method was used to measure the stereotypes of lesbians held by heterosexual college students in the United States. Lesbians recruited from college support groups were asked to rate themselves on the same set of adjectives. The two sets of adjective ratings were then compared to test the hypothesis that individual members of a stereotyped group do not perceive themselves as fitting the stereotyped image. In addition, comparisons were made between the stereotypes of heterosexuals who knew a lesbian personally and those who did not.

\section{Subjects and Procedure}

Three groups were surveyed. An undergraduate introductory psychology class composed of 19 men (mean age $=19$ years) and 9 women (mean age $=19$ years) was used for pretesting.

A second introductory psychology class composed of 29 men (mean age $=20$ years) and 25 women (mean age $=19$ years) was used to collect the 
information to be compared with the lesbian sample. This class was $4 \%$ senior, $10 \%$ junior, $24 \%$ sophomore, and $61 \%$ freshman (1\% of the subjects did not provide this information).

The lesbian sample was slightly older than the comparison group (mean age $=25$ years) and had a greater percentage of juniors $(20 \%)$, seniors $(24 \%)$, graduate students $(6 \%)$, and nonstudents $(30 \%)$.

\section{Questionnaires}

To survey lesbians, D. C. Viss attended a gay and lesbian club meeting at two separate campuses. At one campus, the survey was administered at the meeting $(n=10)$, and a member of the club was enlisted to hand out the survey to lesbian members who had not attended that particular meeting. Those surveys $(n=10)$ were mailed back to the researcher. At the second campus, group members elected to fill the surveys out on their own time and mail them to the researcher $(n=14)$. The survey consisted of 55 adjectives (e.g., masculine), each followed by a 7-point scale ranging from very descriptive of lesbians (1) to not at all descriptive of lesbians (7). The written instructions said, "Please rate each of the following adjectives on how well it fits with YOUR beliefs about the way lesbians are." The adjectives were compiled partly from previous work on the stereotyping of homosexuals (Simmons, 1965; Staats, 1978) and partly from informal discussions with people about their stereotypes of lesbians.

Twenty-eight undergraduate students from an introductory psychology class rated the 55 adjectives on the basis of how descriptive they believed these adjectives were of lesbians. Only those adjectives $(n=21)$ chosen by $50 \%$ or more of the sample as being very descriptive or not at all descriptive of lesbians were retained.

The only exception to this criterion was the adjective masculine, which was chosen by $46 \%$ of the subjects as very descriptive of lesbians. The following 21 adjectives were used: attractive, religious, insecure, ambitious, aggressive, emotional, open-minded, confused, loving, masculine, perverted, submissive, mentally healthy, stable, abnormal, conservative, frustrated, unconventional, individualistic, popular, and sophisticated.

Although the nonlesbian sample was predominantly male (19 men and 9 women), there were no significant differences between men's and women's ratings.

The final list of 21 adjectives was rated by an introductory psychology class and three groups of lesbians. The surveys given to the heterosexual sample and the lesbian sample varied slightly. The heterosexual sample was given a survey identical in format to the 55-item survey already described, but with only the 21 adjectives identified in pretesting. At the end of the 
survey, an additional question was asked: Have you ever had a lesbian friend or acquaintance? Subjects responded yes or no.

The lesbian group was given the same list of 21 adjectives and were instructed to rate themselves on the 7-point scale. The final two questions differed. The first was, "Thinking about the non-gay people that you know, what proportion of them do you believe had stereotypes of lesbians before knowing you were gay?" Response options were almost all, several, some, a few, and no one. The second question was, "If so, to what extent do you think those stereotypes decreased as those acquaintances got to know you?" Response options were a lot, some, a little, none, and don't know.

Both questionnaires were given to the heterosexual samples at the beginning of a class session. We verbally emphasized the importance of honest responses and that the survey responses were anonymous.

\section{Results}

The results generally support the hypothesis that the self-perceptions of lesbians differ significantly from the stereotypes of nonlesbians. Independentsample $t$ tests were used to compare the adjective ratings of the heterosexuals and the lesbians. Table 1 displays the means and standard deviations of the 16 adjectives that yielded significant differences between heterosexuals' and lesbians' ratings. Five adjectives did not show a significant difference between the two groups: religious, aggressive, conservative, unconventional, and individualistic. Comparisons of heterosexuals who did and did not have a lesbian friend or acquaintance yielded no significant differences in adjective ratings.

When lesbians were asked about the proportion of nongay people who had stereotypes of lesbians before knowing they (the lesbians) were gay, $6 \%$ said a few, $12 \%$ said some, $23 \%$ said several, and $56 \%$ said almost all. When lesbians were asked about the extent to which they thought that those stereotypes decreased as their acquaintances got to know them, 56\% said a lot, 32\% said some, $3 \%$ said a little, and 6\% said don't know.

\section{Discussion}

The hypothesis that stereotypes of outgroups are not congruent with outgroup members' self-perceptions was strongly supported. Both heterosexuals and lesbians used 21 adjectives to rate the characteristics of lesbians. Of those 21 adjectives, only 5 did not show any significant differences.

Although the heterosexuals' adjective ratings were significantly different from those of the lesbians, they were not extremely negative (a mean of 4.05 on a 7-point scale). This suggests that individuals' perceptions of lesbians in the United States are continuing to improve. 


\begin{tabular}{|c|c|c|c|c|c|}
\hline \multirow[b]{2}{*}{ Adjective } & \multicolumn{2}{|c|}{ Heterosexuals } & \multicolumn{2}{|c|}{ Lesbians } & \multirow[t]{2}{*}{$t$} \\
\hline & $M$ & $S D$ & $M$ & $S D$ & \\
\hline Attractive & 5.15 & 1.52 & 2.38 & 1.10 & $9.18^{* * *}$ \\
\hline Insecure & 3.94 & 1.62 & 4.74 & 1.40 & $-2.35^{*}$ \\
\hline Ambitious & 4.09 & 1.28 & 2.79 & 1.30 & $4.61 * *$ \\
\hline Emotional & 3.69 & 1.44 & 2.62 & 1.02 & $3.77 * * *$ \\
\hline Open-minded & 3.43 & 1.97 & 2.03 & 1.31 & $3.61 * * *$ \\
\hline Confused & 3.24 & 1.72 & 4.68 & 1.39 & $-4.11 * * *$ \\
\hline Loving & 3.52 & 1.67 & 1.74 & 1.12 & $5.51 * * *$ \\
\hline Masculine & 3.87 & 1.87 & 5.00 & 1.39 & $-3.03 * *$ \\
\hline Perverted & 3.72 & 1.83 & 6.38 & 1.30 & $-7.38 * * *$ \\
\hline Submissive & 4.20 & 1.45 & 5.47 & 1.33 & $-4.13 * * *$ \\
\hline Mentally healthy & 4.69 & 1.79 & 2.29 & 1.27 & $6.79 * * *$ \\
\hline Stable & 4.31 & 1.55 & 2.41 & 1.13 & $6.18 * * *$ \\
\hline Abnormal & 3.07 & 2.05 & 5.94 & 1.46 & $-7.09 * * *$ \\
\hline Frustrated & 3.61 & 1.58 & 4.53 & 1.70 & $-2.58 *$ \\
\hline Popular & 5.48 & 1.44 & 3.09 & 1.38 & $7.65^{* * *}$ \\
\hline Sophisticated & 4.85 & 1.43 & 3.22 & 1.29 & $5.30 * * *$ \\
\hline
\end{tabular}

Note. For heterosexuals, $n=54$; for lesbians, $n=34$. The adjective scale ranged from very descriptive (1) to not at all descriptive (7).

${ }^{*} p<.05 .{ }^{* *} p<.01 .{ }^{* * *} p<.001$.

It was surprising to find that knowing a lesbian did not significantly change heterosexuals' adjective ratings. This finding can be interpreted in two ways. Either the lesbian who was personally known was perceived as an exception to the rule, or she was selectively perceived in such a way as to confirm the stereotype. The former explanation is suggested by some research (Frieze et al., 1978; Hamilton, 1979), and the latter interpretation is supported by other research (Snyder \& Uranowitz, 1978). Most of the lesbians in this study believed that the stereotypes of lesbians held by their nongay acquaintances did change as they became better acquainted. However, knowing a lesbian personally did not affect heterosexuals' ratings. This suggests that stereotype holders maintained their stereotype but relaxed its application to the individual lesbian(s) they knew. Asking respondents to rate the lesbians they know on the same adjectives used to rate lesbians as a group would provide a more definitive explanation for this finding.

It is difficult to generalize the results of this study, which was based on a college sample, to the general population. Furthermore, the heterosexual sample was relatively young, especially in comparison with the lesbian sample. The lesbian sample also included nonstudents. Another weakness of 
the study was that respondents were not directly asked in any of the surveys whether they were, in fact, heterosexual, homosexual, or bisexual. Therefore, it is uncertain that the lesbian group comprised only lesbians. The same is true for the heterosexual sample.

Although this study supports other studies (Staats, 1978) that show improvement in the perception of homosexuals, there was still a significant difference in the way heterosexuals saw lesbians and the way lesbians saw themselves. The finding that knowing a lesbian did not affect heterosexuals' ratings of lesbians in general is disturbing because it suggests that such stereotypes are resistant to change. However, only a small percentage of lesbians are open about their homosexuality. If more lesbians were open about their sexual orientation, the heterogeneity of lesbians as a group might become more apparent. Unfortunately, current stereotypes and resulting discrimination make most lesbians reluctant to share this information.

\section{REFERENCES}

Aguero, J. E., Bloch, L., \& Byrne, D. (1984). The relationships among sexual beliefs, attitudes, experience, and homophobia. Journal of Homosexuality, 10, 95-107.

Amir, Y. (1969). Contact hypothesis in ethnic relations. Psychological Bulletin, 71, 319-342.

Berger, G., Hank, L., Rauzi, T., \& Simkins, L. (1987). Detection of sexual orientation by heterosexuals and homosexuals. Journal of Homosexuality, 13, 83-101.

Carroll, J. S., \& Payne, J. W. (1976). Cognition and social behavior. Hillsdale, NJ: Erlbaum.

Frieze, I. H., Parsons, J. E., Johnson, P. B., Ruble, D. N., \& Zellman, G. L. (1978). Women and sex roles: A social psychological perspective. New York: Norton.

Hamilton, D. L. (1976). Cognitive biases in the perception of social groups. In J. S. Carroll \& J. W. Payne (Eds.), Cognition and social behavior (pp. 81-93). Hillsdale, NJ: Erlbaum.

Hamilton, D. L. (1979). A cognitive-attributional approach to stereotyping. In L. Berkowitz (Ed.), Advances in experimental social psychology (pp. 53-84). New York: Academic Press.

McDonald, G. (1981). Misrepresentation, liberalism, and heterosexual bias in introductory psychology textbooks. Journal of Homosexuality, 6, 45-58.

Morin, S. F., \& Garfinkle, E. M. (1978). Male homophobia. Journal of Social Issues, 34, 29-47.

Myers, D. G. (1987). Social psychology (2nd ed.). New York: McGraw-Hill.

Pettigrew, T. F. (1969). Racially separate or together? Journal of Social Issues, 2, 43-69.

Rosch, E., Mervis, C. B., Gray, W. D., Johnson, D., \& Boyes-Braem, P. (1976). Basic objects in natural categories. Cognitive Psychology, 8, 382-439.

Rosen, D. H. (1974). Lesbianism: A study of female homosexuality. Springfield, IL: Charles C Thomas.

Simmons, J. L. (1965). Public stereotypes of deviants. Social Problems, 13, 223232. 
Snyder, M. (1981). On the self-perpetuating nature of social stereotypes. In D. L. Hamilton (Ed.), Cognitive processes in stereotyping and ingroup behavior (pp. 183-212). Hillsdale, NJ: Erlbaum.

Snyder, M., \& Uranowitz, S. W. (1978). Reconstructing the past: Some cognitive consequences of person perception. Journal of Personality and Social Psychology, $36,941-950$.

Staats, G. R. (1978). Stereotype content and social distance: Changing views of homosexuality. Journal of Homosexuality, 4, 15-27.

Tajfel, H. (1981). Human groups and social categorization. Cambridge, England: Cambridge University Press.

Tajfel, H., \& Turner, J. C. (1979). An integrative theory of social conflict. In W. Austin \& S. Worschel (Eds.), The social psychology of intergroup relations (pp. 33-47). Monterey, CA: Brooks-Cole.

Testa, R. J., Kinder, B. N., \& Ironson, G. (1987). Heterosexual bias in the perception of loving relationships of gay males and lesbians. The Journal of Sex Research, 23, 163-172. 